\title{
IJHG 21.4
}

\section{Global Healthcare for the $21^{\text {st }}$ Century and Beyond}

\section{Introduction}

In considering the present and future state of the world's health, it is worth revisiting the Alma-Ata declaration of 1978 (International Conference on Primary health Care 1978). This international declaration, signed almost forty years ago confirmed the World Health Organisation (WHO) definition of health from the 1946 WHO Constitution as 'a state of complete physical, mental and social well-being and not merely the absence of disease or infirmity' (Office of the High Commissioner for Human Rights 2015). The declaration clearly stated that health is a universal human right and that the gross inequalities in health apparent at the time of the conference, between and within countries were unacceptable. Governments were charged with the responsibility for the health of their populations; the right of people to participate individually and collectively in health care planning and implementation was also highlighted. The Alma-Ata declaration went on to identify primary health care as the most effective medium for achieving these goals.

\section{Global health care inequalities}

Despite the Alma-Ata goal of acceptable health care for all by the year 2000, gross inequalities continue to condemn the world's poorer and disadvantaged citizens to inadequate levels of health and health care. Articles in this issue describe important history, cultural influences and political events leading to this disparity, as well as current challenges and model programmes that inform our path forward. They also show the global influence of the American for-profit model of health care as a commodity, which leads to to unnecessary excesses for those with the money to pay for them (Shah 2011) along with high levels of health inequality in the US where healthcare is provided through a complex system of private insurance, state and federally funded programmes. The concept of health care as a commodity is expensive but not cost effective; the USA spends more than any other industrial nation on its healthcare, yet ranks lower in many health outcomes (Shah 2011). Restriction to medical education, high physician salaries and medical regulation of other health professions adds to the cost of American health care. However, the growing problem with the commodification of health care is that it is no longer restricted to the USA. India, for instance, has adopted major elements of this model as the country moves even farther away from the recommendations of the Bhore committee (Bhore 1946) that articulated the original vision for India's health care (Chavi and Singh 2016). The Bhore committee, like the Altma-Ata declaration, recognised primary care as the most effective vehicle for establishing a modern health care system in India. Yet even now, seventy years later, recommendations such as the doctorpatient ratio have never been realised (Chavi and Singh 2016). 
The colonial legacy in India itself initially caused inequalities in the health care system as health services were focused more on health needs of British colonists than on the needs of the indigenous population (Nayar 2011). Under British rule private health care was encouraged, as this was the model that existed in Britain before the recommendations of the Beveridge report for universal health care (Chavi and Singh 2016). This meant that the infrastructure left at the time of independence was inadequate to meet the needs of a large population, although nominally, policy favoured the health-for-all model on which the British National Health Service (NHS) would be based (Chavi and Singh 2016). Today, India's health care is a mix of public and private care, which reinforces the curative rather than preventative model of health care, caters to medical tourism and places health care in the expensive hands of highly trained doctors. An alternative model would have been to license a second level of medical professionals and equip them with the skills to work in under-served rural areas of the country within a holistic model of healthcare focusing on public health initiatives designed to improve overall health in disadvantaged populations. (Nayar 2011).

\section{Cultural genocide and First Nations' health}

A mis-match between the wisdom and needs of an indigenous population, versus the colonial medical model can also be seen in the past inadequacies in treatment of health care to First Nations populations in Canada. Until as recently as the 1990s, First Nations cultural integrity was not valued by the Canadian government when young people from First Nations communities were routinely removed from their families and culture for education at state run boarding schools (Reading, Loppie, and O'Neil 2016). Education was secondary to the expressed goal of indoctrination into the dominant Euro-Christian society (Truth and Reconciliation Commission (TRC) 2015). The goal of the Canadian government was no less than cultural genocide. Cultural spiritual practices and native languages were outlawed while women were denied their traditional cultural power by enforced adoption of a Eurocentric patriarchal social model. The trauma of this policy was further compounded by frank physical and sexual abuses in boarding schools. While that era has ended, reconciliation is now at a significant, albeit, early stage. According to First Nations elders, an important facet of any reconciliation process must be reconciliation with nature expressed in a strong respect for the environment and a commitment to live in harmony with the natural world (TRC 2015). The concept of nature and our relationship as central to an understanding of health in the $21^{\text {st }}$ century and beyond is echoed by Hancock et al (2016) who argue that the changes to earth's environment caused by human populations is now so great that the impact of these on human health and how we can mitigate them must be at the forefront of any considerations of health governance, now and into the future.

\section{Reconciliation and knowledge sharing}

Living conditions imposed on First Nations communities lost this essential acknowledgement of the importance of the natural environment when considering the health of their people. This was reflected in the cultural appropriation evident in other aspects of community life and governance. Health care goals reflected the medical ideology of the Canadian government with a 
focus on curing disease rather than the holistic interpretation of life and health embedded in the traditional culture of First Nations communities. Fragmentation of care, due in part to overlaps between Provincial responsibilities for health care and Federal responsibilities for First Nations' Health through the Indian Act, administered through Health Canada's First Nations and Inuit Health Branch (FNIHB) made negotiating change difficult (O'Neil et al 2016). A lack of clarity about responsibilities added to the burden of a health care system, which was not focused on needs identified by the populations being served.

In 2005 the issues around First Nations health care needs began to be addressed with a series of agreements between First Nations and Provincial and Federal governments in Canada. These have resulted in a system of governance for First Nations health in one Canadian province, which addresses needs in a way that honours the perspective of individuals from the First Nations and incorporates a unique philosophy of health care which views health as integrated into a person's or community's total well-being, rather than as an absence of a specific disease (FNHC 2016). In fact this closely reflects the interpretation of health promoted by the WHO for all people in our modern global society (Evans and Van Lerberghe 2008).

\section{Health challenges arising in the Anthropocene epoch}

Problems related to maintaining healthy populations in the Anthropocene, a proposed title for our current geological epoch where human activities have begun to have a significant and recognisable impact on Earth's systems (Whitmee et al 2015), have been a matter of discourse for some time. Recently this discourse is becoming more clearly articulated as governments and health care providers gain a better understanding of the challenges associated with climate change and other planetary effects of human actions. Bettcher and Lee (2002) writing about public health, discussed issues around globalisation and health risks associated with complex interactions between the ecosystem and the global economy. They predicted that economic, social and environmental factors will be increasingly acknowledged as important determinants of health and highlighted pollution as an urgent problem impacting on population health. A recent Lancet report on planetary health (Whitmee et al 2015) made the link between environment and health very specific with a stark warning that "Health effects from changes to the environment including climatic change, ocean acidification, land degradation, water scarcity, over exploitation of fisheries and biodiversity loss pose serious challenges to the global health gains of the past several decades and are likely to become increasingly dominant during the second half of this century and beyond" (p.1973). Hancock et al (2016) add the dangers of toxic persistent organic pollutants (POPs) for which there are currently no known methods of detoxification. The real danger lies in our lack of knowledge, making it impossible to predict the long-term health outcomes associated with such insidious pollutants. Hancock et al (2016) also discuss the role of health care facilities, both in their past contributions, and in the measures they must now take to address climate change. 


\section{Discussion}

The problems associated with global future health are immense and will undoubtedly be debated for many years to come. What, if anything, can the articles reviewed here, and other associated information tell us about how to move health governance forward in order to meet the very real needs of the $21^{\text {st }}$ century and beyond? First of all reflecting on these articles should make a strong case for the reality of climate change and the deleterious effect this is already having on human health. The rate of adverse impact on global health will accelerate as our planet becomes increasingly affected by human activity. It is both confusing and unacceptable that one of the most influential nations in the global health care community has a large number of individuals in leadership positions who continue to either deny climate change altogether, or refuse to acknowledge human responsibility. A lack of respect for the scientific method makes organised international action challenging. Secondly, we need to move away from a focus on curative medicine to improve population health through understanding and attempting to mitigate specific risks, many of which are caused by human action or inaction. Central to this is the provision of clean air and water and access to toxin and pollution free foods as a human right. Adequate shelter, income, education and access to health care, particularly reproductive health care for women, are also human rights, which contribute to the health and well being of both individuals and communities. The only way to achieve these goals is to reject the commodification of health care. When health care is profit driven it becomes about maximizing profit rather than about improving health.

The third prong of this trident to improve global health governance is respect for and reconciliation with First Nations communities around the world. Such communities have the right to identify their own health care requirements and culturally-appropriate models of care. First Nations cultural beliefs and practices, which have up until now been dismissed, demonised or outlawed, may actually contain previously unappreciated knowledge about the physical and spiritual balance inherent in defining a healthy community. It is possible that herbal medicines or shamanistic practices, previously ignored or dismissed by the dominant culture, may provide unconsidered solutions for health care problems facing all of us in this very challenging epoch.

\section{References}

Bettcher D, Lee K (2002) Globalisation and public health J Epidemiol Community Health 56: 8-17

Bhore J (1946) Report of the Health Survey and Development Committee Survey Vol 1 Delhi: Manager of Publications

Chhavi S and Singh P (2016) Health service system in transition: an assessment of the influence of the influence of the British and US healthcare systems on the evolution of health services in India. IJHG 21.4 
Evans T and Van Lerberghe W (2008) Primary Health Care. Now More Than Ever Geneva: WHO Press

First Nations Health Council (FNHC) (2016) Social Determinants of Health Accessed 09.10.2016 from: http://fnhc.ca/2016/03/memorandumunderstanding-social-determinants-health/

Hancock T, Capon A, Dietrich U, Patrick R (2016) Governance for health in the anthropocene $I J H G 21.4$

International Conference on Primary Health Care (1978) Declaration of Alma-Ata International Conference on Primary Health Care, Alma-Ata USSR 6-12 September 1978

Nayar KR (2011) Gaps in goals: the history of goal-setting in health care in India Oman medical Journal 26 (1): 1-3

Office of the United Nations High Commissioner for Human Rights (2015) The Right to Health (Fact Sheet no. 31) Geneva: WHO Press

O’Neil J, Gallagher J, Wylie L, Bingham B, Lavoie J, Alcock D, Johnson H (2016) Transforming First Nations' health Governance in British Columbia IJHG 21.4

Reading J, Loppie C, O’Neil J (2016) Indigenous health systems governance: from the Royal Commission on Aboriginal People (RCAP) to Truth and Reconciliation Commission (TRC) IJHG 21.4

Shah A (2011). Health Care Around the World. Global Issues. 22 Sep. 2011. Web. 06 Oct. 2016. <http://www.globalissues.org/article/774/health-care-aroundthe-world>.

Truth and Reconciliation Commission of Canada (TR) (2015) Honouring the Truth, Reconciling the Future Summary of the Final Report of the Truth and Reconciliation Commission of Canada. Accessed 09.10.2016 from:

http://www.trc.ca/websites/trcinstitution/File/2015/Honouring the Truth Re conciling for the Future July 23 2015.pdf

Whitmee S, Haines A, Beyrer C, Boltz F, Capon AG, de Souza Dias BF, Ezeh A, Frumkin H, Gong P, Head P, Horton R, Mace GM, Marten R, Myers SS, Nishtar S, Osofsky SA, Pattanayak SK, Pongsiri MJ, Romanelli C, Soucat A, Vega J, Yach D. (2015) Safeguarding human health in the Anthropocene epoch: report of the Rockefeller Foundation-Lancet Commission on Planetary health The Lancet 386 (10007): 1973-2028 
